\title{
Looking For Metaphor In All The Right Ways
}

\section{Introduction}

The incredible boom in metaphor studies in the last twenty years has brought with it a growing belief in the ubiquity of metaphor in human experience. Beginning with the seminal work of Lakoff, Johnson, and other cognitive linguists Lakoff, 1987; Lakoff \& Johnson, 1980, 1999; Lakoff \& Turner, 1989; Johnson, 1987; Sweetser, 1990; Turner, 1991), scholars in almost every academic field have argued that metaphor has a prominent role in the ways people think, speak, and experience their own lives. Moreover, scholars also claim that many scholarly topics and theories are deeply metaphorical, including ones from the natural sciences such as mathematics and physics (Gibbs, 1994; Lakoff \& Nunez, 1998).

Despite these significant developments in metaphor theory, scholars in a variety of disciplines continue to criticize cognitive linguistic work for it advocacy of metaphor as a major part of the foundation of both thought and anguage (Honeck, 1997; Murphy, 1996; Quinn, 1992; Verkeake \& Kennedy, 1996). Metaphor, according to this alternative view, is at best a handy rhetorical device for illuminating aspects of human knowledge, especially in communicative situations. Yet the essential foundation of human thought is nonmetaphorical, or literal.

This debate about the ubiquity of metaphor in everyday thought and language is too often characterized in polarized terms. For instance, one of the significant misunderstandings about the metaphor movement, which is part of what Lakoff and Johnson (1999) refer to as "second-generation cognitive science", is that all drought and language is inherently metaphorical. Although some scholars in the distant past have indeed made such a grandiose claim (e.g, Vico, Rousseau, Nietzsche), this was never Lakoff and Johnson's intention (1980). For instance, 
in their new book Phidosophy in the flesh, Lakoff and Johnson explicitly acknowledge that many aspects of thought and language are directly understood, in the sense of being perceived and interpreted without the use of metaphorical mappings (e.g., "The pervasiveness of primary conceptual metaphor in no way denies the existence of nonmetaphorical concepts. Quite the contrary... there is avast system of literal concepts... All basic sensorimotor concepts are literal." Lakoff \& Johnson, 1999: 58).

We believe that arguments about the metaphorical nature of human thought and experience mistakenly focus on general theoretical statements rather than on direct empirical possibilities. As Gibbs (1994) noted "We should not simply focus on whether the mind or culture is inherently metaphorical or nonmetaphorical. Rather we should focus our attention on the explicit, detailed examination of various concepts to determine the ways in which these are constituted by both metaphorical and nonmetaphorical schemes of thought" (Gibbs, 1994: 206).

Our aim in this article is to describe some of the important ways to look for metaphor in language, thought, and experience. An important part of our message is that scholars should respect the admonition to carefully examine particular concepts and domains of experience to determine what parts of these may, and may not be, metaphorical. We provide a brief overview of several case studies, from a wide variety of domains, that show the importance of metaphorical thought in people's ordinary conceptualizations of their activities, their language, and their understanding of other people and objects in the real-world. In each case, we note some of the skeptical responses to the idea that metaphor influences people's conceptualizations of some domain of experience. We then go on to show how researchers have looked for metaphor in thought, language, and embodied action. These empirical studies illustrate not only how to look for metaphor in the right ways, in different contexts, but also support the general claim that metaphor is, at the very least, an essential aspect of how people make sense of their experience. An important constraint on the search for systematic patterns of metaphorical thought is to see the connection between embodiment and the way people speak of, and think of, their experiences.

\section{A First Example}

A wonderful illustration of the importance of metaphor in language and thought comes from examination of how Apache Indians in North America name the parts of automobiles (Basso, 1990). In metaphor, one thing stands for another, or a thing is called by a name for something else. For example, in the Couer d'Alene Indian language, the tires of a car or truck become "wrinkled feet," a reference 
to the pattern on their treads. The new knowledge of automobiles is liked to the old knowledge of the body. Basso has described an entire system of naming the parts of motorized vehicles in the language of the Western Apache of east-central Arizona. The Western Apache have extended the names for the body parts of humans and animals to refer to the parts of automobiles and pickup trucks. In this structural metaphor, the hood became the nose (bichili), the headlights became the eyes (bidaa), and the windshield became the forehead (bita). The term for the face (binii) was extended to the whole area extending from the top of the windshield to the front bumper, so this term included the nose/hood and forehead/ /windshield as subparts. The front wheels became the hands and arms (bigan), while the rear wheels became the feet (bikee). All the items under the hood wer classified as parts of the innards (bibye). Under the hood, the battery became the liver (bizig), the electrical wiring, the veins (bit qqs); the gas tank, the stomach (bibid)', the distributor, the heart (bijii; the radiator, the lung (bijii izole)" the radiator hoses, the intestines (bich'i).

There is an underlying conceptual metaphor, MOTOR VEHICLES ARE HUMAN BODIES, which expresses correspondences between the parts of human beings and the parts of cars and trucks. In the MOTOR VEHICLES ARE HUMAN BODIES metaphor, the thing of which we speak (the motor vehicle), with its constituent parts and relations (its cognitive topology), is the target domain, while the thing with which we refer (human bodies), with its own constituent parts and relations, is the source domain. The naming of vehicle parts with the names of human body parts preserved the hierarchical cognitive structure of relationships among the parts so that both the car's body and the human body has "innards" that included, for instance, "liver".

Some scholars might skeptically argue that how people in one culture name parts of automobiles may not be the best place to find evidence of metaphoric thinking. But the Coeur d'Alene names for automobiles reveals a deep-seated, cognitive imperative to make sense of the world in terms of metaphor. More importantly, the metaphoric understanding of the automobile is done in terms of people's own bodies and embodied experience. By recognizing how parts of an automobile have a metaphorical relationship to human body parts (and functions), the Western Apache has created something new using their imaginative processes to the fullest. The Western Apache has in a sense reordered their experiences by looking at something different than before. Yet this reordering of experience is not merely cliched, or a one-shot mapping. Instead, there is a complex system of metaphorical mappings that has as its roots people's ordinary experiences of the human body. As we'll see in the rest of the article, the human body often is the main source domain for many pervasive conceptual metaphors, and, as such, is one of the best places to look for metaphoricity in language, thought, and culture. 


\section{Metaphorical Thought In Understanding Metaphorical Language}

One topic where the debate over metaphor in thought has perhaps generated the greatest amount of empirical data concerns people's understanding of metaphorical language. Traditional views of figurative language assume that metaphor, irony, metonymy, and so on, require more cognitive effort to understand than literal speech, primarily because figurative language is seen as linguistically, and cognitively, deviant (Grice, 1975; Searle, 1979). But the results of many psycholinguistic studies, which measured how long it takes people to process figurative, as opposed to literal, statements, demonstrated that people can understand figurative language as quickly as literal speech, especially when these expressions are encountered in realistic social contexts (see Gibbs, 1994 for review). Various other studies support the idea that figurative language is easy to produce and understand because people actually conceptualize of their experiences in figurative (e.g., metaphorical, metonymic) terms (Gibbs, 1994).

For instance, a good deal of empirical evidence from cognitive psychology and psycholinguistics has demonstrated the psychological validity of many of the ideas about conceptual metaphor from cognitive linguistics (Gibbs, 1994). Psycholinguistic evidence supports the idea that idea that metaphors such as ANGER IS HEATED FLUID IN A CONTAINER are really conceptual and not, more simply, generalizations of linguistic meaning. These include experimental studies that have looked at people's mental imagery for idioms (Gibbs \& O’Brien, 1990), people's context-sensitive use of idioms (Nayak \& Gibbs, 1990; Gibbs \& Nayak, 1991) and euphemistic phrases (Pfaff, Gibbs, \& Johnson, 1997), people's folk understanding of how the source domains in conceptual metaphors constrain what idioms (Gibbs, 1992) and proverbs mean (Gibbs, Strom, \& Spivey- Knowlton, 1997), people's use of conceptual metaphors in organizing information in text processing (Allbritton, McKoon, \& Gerrig, 1995), and people's use of conceptual metaphors in drawing inferences when reading poetic metaphors (Gibbs \& Nascimento, 1996). These psycholinguistic findings support the hypothesis that different kinds of metaphoric thought partly explain why many metaphors and idioms have the meanings they do for contemporary speakers.

The claim that pre-existing conceptual metaphors influence all aspects of how people understand idiomatic and conventional language has been criticized by scholars interested in immediate metaphor and idiom comprehension (Glucksberg \& Keysar, 1990; Glucksberg, Brown, \& McGlone, 1993; Kreuz \& Graesser, 1991; McGlone, 1996). These researchers argued that the intuitions of cognitive linguists is insufficient to support the idea that conceptual metaphors are automatically employed during discourse comprehension. This is indeed 
a legitimate criticism. But even more recent research on on-line idiom processing shows that people appear to quickly activate underlying conceptual metaphors when reading idiomatic phrases arising from these same metaphors (Gibbs, Bogdonvich, Sykes, \& Barr, 1997).

A very important element of these recent on-line studies, consistent with the above mentioned research, is that each one explicitly seeks to find whether metaphorical knowledge influences some aspect of metaphorical language understanding. Few critics of the possible role of conceptual metaphors in language use explicitly seek empirical evidence to confirm their ideas. They make theoretical, or meta-theoretical, statements against the idea that conceptual metaphor constrains the psychology of language use, but rarely do they set up experimental situations to contrast their own views against the claims of conceptual metaphor theory. Our view is that researchers must first look to find metaphor in thought and language, and then fail to find it, before they can claim that conceptual metaphors are not part of people's ordinary psychological reality.

It is also important to note that the psycholinguistic studies described here employ appropriate indirect methods for assessing people's cognitive processes used when speaking and listening. Thus, these studies do not rely on the linguistic mentions of language theorists to distinguish between varying theoretical accounts of metaphorical language use. Instead, these studies employ techniques that ask participants, who are ignorant of the hypotheses tested, to imagine expressions, read them in a speeded manner, make various speeded and non-speeded judgments about metaphors, or to match verbal expressions according to their similarity of meaning. Researchers then analyze the results from these different experimental tasks and draw inferences about the underlying cognitive operations and knowledge required to causally produce participants' laboratory behavior. Our argument is that these indirect methods from cognitive psychology are essential if we are to infer anything about rapid, mostly unconscious mental processes. This is an important lesson to understand in knowing how to look for metaphor in language and thought.

\section{Metaphoric Representations And Embodied Experience}

another question that linguists and psychologists have debated concerns why certain conceptual metaphors, but not others, are used by people in speaking about abstract concepts? There is a large body of work in cognitive linguistics

suggesting that much metaphorical thinking arises from recurring patterns of embodied experience (Johnson, 1987; Lakoff, 1987, 1990). For example, central to our understanding of the conceptual metaphor ANGER IS HEATED FLUID IN A CONTAINER. which gives 
the ceiling, make my blood boil, is the embodied experience of containment. People have strong kinesthetic experiences of bodily containment ranging from situations in which bodies are in and out of containers (e.g., bathtubs, beds, rooms, houses) to experiences of bodies as containers in which substances enter and exit. An important part of bodily containment is the experience of our bodies being filled with liquids including stomach fluids, blood, and sweat. Under stress, people experience the feeling of their bodily fluids becoming heated. These various, recurring bodily experiences give rise to the development of experiential gestalts, called an image schemas, such as for CONTAINMENT (Johnson, 1987).

There are several studies from cognitive psychology that supports the idea that people's embodied experiences gives rise to their metaphorical structuring of abstract concepts, which, in turn, constrains speakers' use and understanding of language. An important part of these studies is how they explicitly look for embodied metaphor in ordinary language use. In particular, the researchers employ the strategy of (a) doing cognitive linguistic analyses to discover possible patterns of embodied metaphors, (b) then independently investigate people's understanding of the source domains for these embodied metaphors, especially in terms of their embodied understandings of these domains apart from their use in linguistic expressions, and then (c) use the data from these independent analyses of embodied source domains to make predictions about what gets mapped onto different target domains in conceptual metaphors.

For instance, one set of psycholinguistic studies examined people's intuitions of the bodily experiences of containment and several other image schemes, which serve as source domains for several important conceptual metaphors, underlie speakers' use and understanding of idioms, such as blow your stack, flip your lid, and hit the ceiding, each of which roughly mean "to get very angry" (Gibbs, 1992). These studies were designed to show that the specific entaihnents of idioms reflect the source to target domain mappings of their underlying conceptual metaphors (Gibbs, 1992). Most importantly, these metaphorical mappings preserve the cognitive topology of these embodied, imageschematic source domains.

Participants in a first study were questioned about their understanding of events corresponding to particular bodily experiences that were viewed as motivating specific source domains in conceptual metaphors (e.g., the experience of one's body as a container filled with fluid). For instance, participants were asked to imagine the embodied experience of a sealed container filled with fluid, and then they were asked something about about causation (e.g., What would cause the container to explode?), intentionality (e.g., Does the container explode on purpose or does it explode through no volition of its own?), and manner (e.g., Does the explosion of the container occur in a gentle or a violent manner?).

Overall, the participants were remarkably consistent in their responses to the various questions. To give one example, people responded that the cause of 
a sealed container exploding its contents out is the internal pressure caused by the increase in the heat of the fluid inside the container. They also reported that this explosion is unintentional because containers and fluid have no intentional agency, and that the explosion occurs in a violent manner. These brief responses provide a rough, nonlinguistic profile of people's understanding of a particular source domain concept (i.e., heated fluid in the bodily container). These profiles are rough approximations of what cognitive linguistics and others refer to as the image-schematic structures of the source domains (Gibbs \& Colston, 1995; Lakoff, 1990; Turner, 1991, 1996).

These different image schematic profiles about certain abstract concepts allowed Gibbs to predict something about people's understanding of idioms. The idea was that people's intuitions about various source domains map onto their conceptualizations of different target domains in very predictable ways. For instance, people's understanding of anger should partly be structured by their folk concept for heated fluid on the bodily container as described above. Several studies showed this to be true (Gibbs, 1992). Not surprisingly, when people understand anger idioms, such as blow your stack, flip your lid, or hit the ceiling, they inferred that the cause of anger is internal pressure, that the expression of anger is unintentional, and is done is an abrupt violent manner. People do not draw these same inferences about causation, intentionality, and manner when comprehending literal paraphrases of idioms, such as get very angry. Furthermore, people find it easy to process the idiomatic phrase blow your stack when this was read in a context that accurately described the cause of the person's anger as being due to internal pressure, where the expression of anger was unintentional and violent (all entailments that are consistent with the entailments of the source to target domain mappings of heated fluid in a container onto anger). But readers took significantly longer to read blow your stack when any of these entailments were contradicted in the preceding story context.

These psycholinguistic findings provide experimental evidence that people's embodied metaphorical concepts underlie their understanding of what idioms mean in written texts. Such data stand in direct contrast to traditional theories which assume that idiomatic expressions are merely cliched, dead metaphors Cooper, 1986). Moreover, the data from these research projects provide significant experimental evidence that people's intuitions about their embodied experiences can predict something about their use and understanding of idioms, expressions that are partly motivated by bodily-based conceptual metaphors. More recent experimental studies showed that people's understandings of metaphorical expressions about human desires (e.g., I am starved for his affection, I am hungry for power and fame) are motivated by people's embodied experiences related to feeling hunger (Gibbs, Lima, \& Edson, in press). This is true for native speakers of both English and Poriuguese. In particular, people's embodied understanding 
of the variety of ways they experience hunger gets mapped onto their understanding of the abstract domain of human desires.

\section{Metaphor In Narratives About Cancer}

Perhaps the most widely-read book on metaphor in contemporary culture is Susan Sontag's 1977 essay Illness as metaphor. Sontag, a cultural critic, examined the metaphors historically associated with people's understanding of both tuberculosis and cancer, and in a later 1991 book, AIDS. As she cateloged the multiple metaphorical representations of the various sources of cancer, Sontag forcefully argued her main point that "illness is not a metaphor, and that the most truthful way of regarding illness., is one most purified of, most resilient to, metaphoric thinking" (Sontag, 1991: 3).

Sontag's argument against metaphor in thinking about illness parallels in many ways the claim of some cognitive psychologists against metaphor as a fundamental part of ordinary human thought. She essentially maintains that the metaphors seen in people's talk about cancer only reflects rhetorical devices used for communication and do not arise from underlying metaphorical patterns of thought. Yet in making this argument, Sontag, like cognitive scientists critical of the idea that metaphor is part of both language and thought, fails to systematically explore how metaphor may structure people's experience of their bodies and their illnesses.

Several researchers, primarily from the field of medical anthropology, have now explored the importance of culturally-situated metaphors in patients' experience of illness (Scheper-Hughs \& Lock, 1987). These studies note the prominence of different metaphors in the ways patients make sense of their often incohate experiences of illness. For example, DiGiacomo (1992) argued from his interview studies that "No-one ever experiences cancer as the uncontrollable proliferation of abnormal cells. Instead, we can experience anything at all only through and by means of culturally and social reproduced structures of metaphor and meaning" (1992: 117). The vast majority of the anthropological studies highlight the way patients use metaphor to actually experience their illness. Yet these studies do not generally seek to find systematic correspondences across individuals, nor do they seek the underlying embodied, conceptual metaphors that the different linguistic metaphors patients produce tend to exhibit.

To remedy these problems, Gibbs and Frank (in press) interviewed six women who were recovering from different forms of cancer. The six women were individually asked to describe their illness, particularly focusing on how they tried to come to terms with the idea of having cancer, feeling ill, having treatments, and attempting to heal. An analysis of these narratives revealed 796 individual 
linguistic metaphors that reflected 22 different metaphorical concepts. It is notable, first of all, just how prominent metaphor was in the women's narratives. Each person produced on average 132 metaphorical expressions in the 20-30 minute interviews. These metaphorical expressions were certainly not all novel as most reflected highly conventionalized ways of metaphorically understanding different aspects of the women's illness experiences. Yet these conventional metaphors were not simple cliched, dead metaphors, but instantiated enduring, conceptually alive ways of metaphorically structuring the women's understandings of what is happening to them.

The second notable point of the analysis of the Gibbs and Franks's narratives is that the women's embodied experiences, not of the illness itself, but of their more general bodily sensations and knowledge, served as the primary source domains in many of the conceptual metaphors underlying the women's wide range of linguistic metaphors.

Let's consider in some detail the most frequently used conceptual metaphor that motivated the women's metaphorical language. The metaphorical mapping of CANCER IS AN OBSTACLE ON LIFE'S JOURNEY served as the conceptual foundation for over $38 \%$ of all the women's verbal metaphors (and was found frequently in each of the six women's narratives). The CANCER IS AN OBSTACLES ON LIFE'S JOURNEY is based on a higher-level mapping of LIFE IS A JOURNEY, referring to the idea that we are all travelers navigating through life. Based on our conceptual knowledge of journeys we can assume that, like a journey, life has a beginning (birth) and an ending (death). Also, journeys may make use of paths, roads, water, and airways. This knowledge of

journeys is used as the source of information for the target domain, life. For example, a person might say This is the path in life I have chasen or We've reached a bend in the road. In addition, these surfaces are sometimes bumpy, smooth, forked, and even detoured. These characteristics are also mapped onto LIFE AS A JOURNEY and can be used to conceptualize and understand the idea that sometimes a person's life seems to be smooth sailing ahead, a bumpy road, in shallow waters, at the crossroads, or going around in circles. Journeys also require different means of transportation, and this source of knowledge is used when a person says things like I'm just getting back on my feet or My heels are spinning. Furthermore, sometimes paths or roads are blocked or impeded by obstacles, just as life sometimes seems stuck or hard to get through. Based on the mapping LIFE IS A JOURNEY, "states are locations, changes are movements, purposes are destinations, difficulties are impediments to motion,

Long-term purposeful activities are journeys, and so on" (Gibbs, 1994: 152).

The women's narratives in different ways illustrated how cancer is pervasively seen as part of the trip or an obstacle in the journey of life. Cancer is something one "starts" and "finishes" just like a journey. One woman who was recovering 
from breast cancer said, I'd say for about the last year I've felt quite finished with it(cancer)- like it's done. It's over. Participants very frequently talked about cancer and treatments as something to get through, move into, and get over. In this sense, cancer is often seen as something you can travel into and out of, as if cancer were a place.

Another woman specifically stated this when she said that cancer For me, it has been a place in my life to think, to realize, what precious time we have here. One woman, who had had leukemia, said I was in and out of [cancer] very quickly from the day of diagnosis to the day of dismissal. In addition, she said, Because the warning time was virtually none, it (cancer) was very hard to move into. That cancer is a place on life's road that is different than everyday places on life journey is evident in the same woman's narrative when she said, ... the transition (out of cancer) looks like it depends on how much of your life you're able to step back into-like if you have work and family and roles that you can step back into that were interrupted when you did cancer, and you are able to just step back into them, it seems ...like getting back into one's life isn't that difficult but for me I felt like all of my structure was gone, and it was very slow. This woman talks about cancer as if it were a physical step off of life's normal path. Cancer, in this sense, is in a different place, or on a different path, than one would normally travel along, and states of being are places one can step into and out of.

Cancer sometimes challenges the path one has traveled in the past; questioning whether the path was a healthy and safe one. One woman said that after she had been treated for breast cancer she realized that her past career was not satisfying for her She said, 1 wasn't going to deal with cancer and chemotherapy to get well to go back and do something 1 didn't like to do. Cancer may so drastically call into question of a former path that when a person is diagnosed with cancer, she may have feelings of "disorientation," as one participant described in talking about the time after she had breast cancer: To have breast cancer was like walking off the face of the earth. It felt like-I tell people T... decided that when they s'y abut the world being round is just a lie. It's true. It's flat, and I know what the edge looks like. 'You know that's what it felt like ... I had absolutely nowhere to go. When one's former life journey is challenged, one's life is also called to be re-examined. Cancer can change people's life-courses by showing or providing them with alternate paths to consider as new experiences are to be had.

The women in the study talk about cancer changing the directions of their lives. For example one woman said, I felt like to see that there is the potential for growth from the crisis of dealing with the health issue and that growth being the chance to change the course of my-life while I'm still young, and I have a lot of, hopefully, a lot of life left to live. Another woman said that having cancer 
made her realize that this is life-this is it. It is not about getting somewhere else. When one is sick with cancer, in recovery from surgery, or having reactions to treatment, one is usually forced to spend a great amount of time lying or sitting down, resting. When one is physically "down" one is not able to journey neither literally nor symbolically. A different woman who had breast cancer said that after chemotherapy It took me a long time to get back on my feet. Another woman who also had breast cancer said that chemotherapy stopped me... 1 was sitting or actually lying down for most of that time resting. Finally, cancer not only challenges the course of travel, as mentioned earlier, but it threatens to shorten or end the path, ending the "journey" of life. One woman said that through chemotherapy, I just thought that I'm not going to make it.

This analysis of just one prominent metaphor in the women's narratives shows the systematicity among the different conventional metaphorical expressions. Talking about cancer as if one were in a special kind of journey is not merely a cliched way of speaking without any relation to the way these women actually conceptualized of their illnesses. Instead, the various statements discussed here express different aspects of a complex, active conceptual metaphor. Many of the other metaphors revealed in this analysis also refer to embodied source domains, such as EMOTIONAL EFFECT IS PHYSICAL CONTACT and THE SELF IS A CONTAINER AND CANCER IS A FLUID THAT OVERFILLS THE CONTAINER. Again, looking for metaphor in language, thought and experience demands a close examination of the relationships between recurring embodied experiences and metaphorical patterns of thought. It seems clear that if we were to strip metaphors away from the language used in conceptualizing illness, we would be robbing humans of self-awareness, meaning, emotional comfort, and potential growth (Kirmayer, 1993). Metaphors are crucial to the way we uncover deep insights, relate to others, and feel a sense control. Furthermore, the use of metaphor may help the sick to heal because, as Kirmayer points out: “... healing may occur not because a conflict is accurately represented, or even symbolically resolved., but because the metaphorisation of distress gives the person room to maneuver, imaginative possibilities, behavioral options, and rhetorical supplies. (1993: 165).

\section{Metaphor In People's Use Of Computers}

Most people think that computers are far from metaphorical, or related to metaphor in any substantial way. Yet in describing their experiences with computers, people have particular metaphorical ways of talking. For example, when searching for information on the World Wide Web, people say things such as, Let's go to your Web site, I returned to that place with the information about skin cancer, 
I wandered around Yahoo, or Do you remember how you got therel. In these utterances, words or phrases that commonly refer to physical spaces (e.g., there, place) or motion (e.g., go, return, wander) are co-opted to refer to information sources and information actions. Interestingly, these common expressions are systematically used by all computer users and are readily understood by novices with little or no computer experiences.

Some scholars may argue that the particular words used to talk of people's interactions with computers is merely a matter of arbitrary linguistic convention, or that people randomly choose verbs or nouns that they have used in other contexts before. But people do not use just any verb to describe Web actions. For instance, people generally do not use verbs pertaining to flight or other types of vertical motion to convey Web actions. Consider how odd it sounds to say?? I climbed up to his Web page (Maglio \& Matlock, 1999). One might also argue that metaphorical language about the Web is based purely on frequency. For example, the verb go is highly frequent and seen in a variety of contexts. Perhaps computer users just apply this verb to the domain of interacting with the Web. This explanation alone, however, is inadequate because there are many highly frequent words that people do not use to describe Web actions. For instance, the preposition over is highly frequent in English, yet English speakers do not say things such as?? I stayed over the first Web page 1 had seen, preferring to use the preposition at instead. Finally, one could argue that metaphorical language about Web use is based on the similarity of obtaining information on the Web with moving through space. But from any reasonable perspective, moving across a room, through a park, or down a street differs in many respects to navigating on the Web. In using the web, there is certainly the illusion of "motion" along a trajectory toward an information objects, but there isn't the need to avoid bumping into or having to navigate around objects such as tables or other types of furniture as there is with moving across a room. (However, some might conceive of advertisements and other signs of unrequested information as clutter or as being in the way.) Similarly, when using the Web, people do not have to worry about general safety (falling down, running off the road, speeding and so on), as is the case with navigation along a path in a park or on a freeway. Getting lost is also less of a concern. None of these explanations for the metaphoricity in people's talk when using the Web can sufficiently account the data. A full understanding of why certain types of language is used to talk about the Web and not others requires careful systematic linguistic examination and statistical analyses.

Beginning in 1996, before the Web had become so immensely popular, a series of psychological studies interviewed people about their experience using the Web. The results of one study showed a high degree of consistency in the description of their actions. Thus, people used language referring to predominantly twodimensional and to a lesser extent three-dimensional space (Matlock \& Maglio, 
1996). For instance, participants tended to describe Web sites such as homepages with language suggesting a two-dimensional construal as in Then 1 stopped at my friend's homepage or At one guy's web site, I saw some information about surfing. And they described web sites serving as classified indexes (e.g., Yahoo) with language suggesting a three-dimensional construal such as I was going in circles in Yahoo until... or In Yahoo, there was a bunch of information about pure-bred dogs, but I wasn't sure about which [site] to go to so I just clicked on a bunch of different things in there.

In other studies, people (a) often referred to themselves as actively moving along trajectories toward information objects even though they did not travel anywhere at all (e.g., I went from Yahoo to Altavista), (b) rarely referred to themselves as passive recipients (e.g., I waited, and then it brought me the information), which seems more likely considering that in reality the information actually does travel to the user's computer over physical wires, and (c) consistently used language referring to self-directed motion along a path, even inexperienced Web users, in eluding those who had never heard of the Web (Maglio \& Matlock, 1999).

These empirical findings suggest that people often think of their actions on the Web in terms of embodied actions in the world. Under this view, certain conceptual metaphors, such as WEB SPACE IS PHYSICAL SPACE, WEB USER IS TRAVELER, and OBTAINING INFORMATION IS MOVING THROUGH SPACE, enable people to make sense of and to communicate their experiences using the Web (Maglio \& Matlock, 1999; Matlock \& Maglio, 1999).

Metaphorical construal of computers is not limited to people using the Web, or more specifically searching for information on the computer. When describing computers, people routinely use language referring to human attributes or qualities, even if they are not aware of doing so, such as when they say Windows is idiotic, My computer's fussy today, or This laptop is being a moron today. According to Laurel (1997), this very natural phenomenon is based on a tendency to metaphorically think of computers in terms of humans or other living organisms. Why might people do this?

There are several possible reasons why people might personify computers. For instance, human-computer interaction typically involves one-on-one communication (human to computer) much like they do in human-human interaction. More importantly, people anthropomorphize computers because computers appear to have agency, a fundamental human ability. Computers have a considerable amount of responsiveness built into them - they can do or refuse to do things. And as agents, they have a certain amount of influence over how we interact with computers. Consider how natural it is to say things such as Windows won't allow you to have more than operating system running, or (to the computer) Why won't you let me do that'll Or think about how natural it is to 
yell You stupid idiot', or Screw you', at a computer. Such language is not typically used toward other inanimate electronic objects, such dishwashers or toasters.

Metaphorical construal of the personal computer as human-like entity has recently begun to have an impact on computer interface and computer system design. A computer is no longer seen as simply a monitor, a keyboard and CPU. Computer software now includes animated assistants, such as the Microsoft Office paperclip, which moves about in a corner in the screen, vigilantly watching the user and offering help (more often than most would like). Interface designers have moved beyond the two-dimensional desktop metaphor and created more embodied digital environments such as town squares, shopping malls, personal assistants, living rooms that users may interact with other people, use and develop different program and products, and connect with other computer services. Along with this trend comes the desire to design computers that understand and adapt to users' emotional states (see Picard, 1998).

Part of this interest in affective computing stems from a growing body of empirical work that suggest that people view computers as social agents (Dryer, 1999). For instance, when interacting with computers, people often behave politely, hoping not to hurt their computer's feelings. Just as when dealing with other people, computer users prefer interacting with computers with personality characteristics similar to their own (e.g., a dominant personality type prefers to interact with a dominant computer). In addition, people respond to flattery from computers much in the same way that they do to flattery from other people (Nass, Moon, Morkes, Kim, \& Fogg, 1997). These empirical findings strongly suggest that the COMPUTER IS HUMAN metaphor is deeply entrenched in human experience (which is different from the HUMAN IS COMPUTER metaphor that has dominated cognitive science for the past 40 years).

What sort of impact does metaphor have on the design of interfaces? In creating a new user interface, the designer seeks the right metaphor, hoping it will guide the development of the interface and make things easier for the computer user. As Norman (1998) argues, however, many metaphor-based interfaces fail because they do not simplify computing for the user. According to Norman, some metaphor-based features can distract or confuse the user, and others simply fail to be useful. For example, in the Windows operating system, a "window" was originally intended to highlight the notion of easy access and openness (in contrast to MS-DOS, UNIX or other more "opaque" operating systems), and one would expect this to map onto ease in using computers. However, the utility of the metaphor is not obvious. Think about how cumbersome Windows can be given the many options provided by so many menus.

The difficulty here is that most metaphors used in interfaces do not reflect the rich set of mappings provided by embodied conceptual metaphors. In fact, the few interfaces that do incorporate, or at least resonate with conceptual 
metaphors, seem to work well. For instance, most people would agree that Apple Macintosh's Fetch is a well-motivated metaphorically based design. This program allows people to FTP (,file transfer protocol”), or transfer files from one machine to another. In using Fetch, a person sees a small dog "running" in place on the screen, and infers that the dog is "moving" along a trajectory from one "place" to another. What arises from this metaphorical illusion is the tacit understanding that a file is being delivered from one machine to another, and the belief that the dog is "helping" the user. Another good metaphor-based design is the Desktop metaphor, in which written bodies of text are represented as "files" that are contained by "folders". In this environment, information objects, such as files and folders, can be "dragged" into a trash can and "thrown away", much in the same way that they can in a "real" office.

In sum, we have shown that metaphors abound in computer talk, thought, and action. We have also argued that the natural tendency to recruit metaphor in talking about and interacting with computers reflects the human embodied experience.

\section{Metaphor In Interpreting Dance}

Our last case study examines metaphor in nonlinguistic action. One of the great misconceptions about metaphor is that it is primarily, or even solely, a linguistic device that may reftect some aspects of thought, but is not rooted in people's ordinary conceptual structures or their embodied actions. Much of the cognitive linguistic and psycholinguistic research described above clearly repudiates this mistaken notion. But there remain fierce debates in the philosophy of aesthetics, to take one example, about the role of metaphor in understanding the meaning of nonverbal action, in particular dance performances. Thus, some scholars argue that metaphor has little to do with meaning in dance because, so they claim, metaphor is verbal while dance is embodied action (Van Camp, 1996). Other scholars argue that performing dance, and interpreting it, has its foundations in widelyshared patterns of metaphorical thought (Gibbs, 1999; Whittock, 1992, 1997).

Improvisational dance, where the performers act without benefit of a choreographer's directions, provides an interesting example of the idea that metaphor underlie our meaningful experience of embodied action in dance. Take the case of contact improvisation, a dance genre where two or more dancers move spontaneously in close physical contact with each other. Just as two people must coordinate their actions as they improvise in spoken dialogue, contact improvisation, as the name implies, requires dancers to coordinate and cooperate as they lean against and balance on each other, give support or are supported by 
each other, roll on the fioor and over each other, jump up, fall, and perform in various other solo and shared movements. Dancers and observers may not be consciously aware of meaningful patterns as they move and watch. Yet a few moments of reflection on the aesthetic pleasure we receive as dancers and observers clearly suggests that dance, including improvisational dance, taps into important aspects of metaphoricity.

Consider one response to the first few minutes of a contact improvisational dance performance entitled Julian and Alito's Duet, originally presented as part of A Cappella Motion (Gibbs, in press).

Julian and Alito's performance begins with the two dancers walking onto the stage and Julian lying face down on the floor, hands extended in front, and Alito moving over to squat on the back of Julian's thighs. Julian raises his head and shoulders and looks behind to observe Alito and then Julian extends his arms out in front of him. Julian lies back down and Alito moves upward onto Julian's back, balancing himself, arms extended, then stands on Julian's back as Julian once more rises, this time to his hands and knees. Alito sits on top of Julian, riding him, while Julian slowly raises himself to his knees, soon coupling his hands around Alito's feet as Alito wraps his legs around Julian's trunk. Julian stands, walks around the stage and twirls Alito around in circles as Alito twists on Julian's back, extending arms and legs outward in different directions, sometimes using Julian's one extended arm as a guide. Julian then stops walking and slowly pulls Alito around in front of him, and, while still standing, cradles Alito in his arms down by his waist. Alito lies back, and with arms extended over his head and legs extended outward. Julian then forcefully attempts to pull Alito up and Alito jerks spasmodically (audience laughing). Julian then makes the same attempt, and again Alito jerks spasmodically (again the audience laughs).

Even within these first few minutes of Julian and Alito's Duet, one is struck by several specific movements and several general themes that suggest different levels of intentionality on the part of the dancers. The dancers, both individually and in concert, exhibit through a number of movements and positions great symmetry, balance, support, linkage, and emotional involvement and independence. As the performance proceeds, the dancers appear to be on an improvisational journey heading toward some unknown destination that unfolds in front of them. At several moments, both the dancers and the audience appear to be "taken by surprise" as one movement leads unexpectedly into another position and/or movement. The dancers appear to be awakening, coming together, struggling over dif ferent personal and mutual obstacles, experiencing moments of calm, moments of great elation, moving toward places where they are in tight syncronicity; and, at other times, the dancers appear to be feeling each other out for possible new ways to be joined together for their individual and mutual benefit. 
Many aspects of Julian and Alito's performance make use of bodily based metaphors that we recognize for their intentional meaning. For example, various bodily postures and movements express via metaphor different sorts of conventional meanings. Upward movements are suggestive of positive affect, of greater conscious control of one's body and, more generally, of ones life. For instance, there are many moments in Julian and Alito's dance where their upward movements, both while on the ground and while standing, signify positive emotions, especially when they are in balanced positions of contact. On the other hand, downward body postures and movements suggest negative affect, reflecting individuals under stress, in poor health, with little control over their movements or their lives. The opening of Julian and Alito's performance, where Julian lies prone with Alito on top of him, suggests, just for a moment, Alito's control over Julian. At the very beginning Julian lifts his head and looks over his shoulder at Alito as if to question this control. Some of their unsteady movements and positions suggests uncertainty. Falling represents the lack of control, illness, and feelings of debasement. At a later moment in Julian and Alito's dance, Alito runs toward Julian and leaps into his arms, as if wishing to establish a more personal bond between them. But the movement fails because the dancers immediately become unbalanced, yet the two dancers gracefully tumble onto the stage and start anew to establish contact. Throughout the performance, bodily movements that are balanced, whether a dancer is moving or stationed alone or in contact with other dancers, reflect mental, emotional, and moral stability.

In Julian and Alito's dance, movements across the stage reflect aspects of our embodied experience of physical journeys. Here the movement from point A along some path to point B expresses progress toward some concrete or abstract, sometimes personal, goal. One sees the struggle when the dancers first begin a journey (some movement from point $\mathrm{A}$ to point $\mathrm{B}$ ), the obstacles they encounter along the way, how they try, and sometimes fail, to support each other, the times when they seem to be spinning their wheels (including one moment later in Julian and Alito's performance when Alito actually walks briskly in place), until they break free and almost fly toward their long-anticipated goal. Most generally, many aspects of the movements Julian and Alito perform, the movements observers see in their dance, are not interpreted simply as arbitrary physical acts with no sense of purpose or communicative meaning. The basic images in dance are movement structures that are inherently intentional, imaginatively patterned, and flexible, both in terms of their physical instantiation and their metaphorical interpretation.

Dancers are intentionally communicating narratives or stories via combination of various bodily movements, which are reflective of widely shared metaphors. The movements dancers make create the impression of stories that we can understand, not just in the local sense of watching someone move across a stage, 
but in broader terms relating to the human story, our own mundane lives as we struggle to find meaning between order and chaos. Recognition of the metaphoricity in dance is an important element in our experience of the movements not as mere accidents but as beautiful, artistic, meaningful actions.

Our main point in this section is that understanding what is metaphorical about dance requires that one seek systematic correspondences between actual movement and different embodied metaphors. One should not dismiss the idea that some aspects of dance are inherently metaphorical unless one can explain dancers and observers reactions to what they perceive to be meaningful in dance.

\section{Conclusion}

Looking for metaphor in all the right ways demands that researchers acknowledge several meta-theoretical and methodological challenges. First, debates over whether metaphor is, or is not, a significant, ubiquitous part of human thought and language requires scholars to do more than just speculate about reasons why one view is better than another. Arguing, for instance, that metaphor can't be part of ordinary thought because of the inconsistency between different conceptual metaphors for the same topic (Murphy, 1996) assumes without justification that thought must be internally monolithic (Gibbs, 1996). Moreover, to argue that metaphors are just cultural devices and not part of human thought (Honeck, 1997) assumes without justification that culture and human thought are entirely separable. These kinds of arguments provide meta-theoretical excuses for not having to worry about the metaphorical nature of human thought and language. Yet, as we've emphasized, scholars should not dismiss the ubiquity of metaphor in human experience unless they first systematically seek to find metaphor, and then failing to do so, provide alternative accounts of people's linguistic and nonlinguistic behavior.

A related challenge in looking for metaphor in thought and language is to use the right search tool. Thus, linguists' intuitions about the systematicity of metaphor in varying linguistic expressions is perfectly appropriate for exploring the presence of metaphor in the way people speak. Indeed, such evidence is also useful in supporting the idea that people can, at times, make sense of their varying experience in terms of metaphorical thought. But to show that people actively use metaphorical schemes of thought in the online production and comprehension of language demands that specific experimental techniques be employed, especially those developed by scholars in cognitive psychology and psycholinguistics. Fortunately, there is a growing body of evidence to support the claim that conceptual metaphors may be automatically accessed in some manner during some aspects of linguistic processing and in how people conceptualize of their actions when using computers. 
At the same time, discourse analyses of what is metaphorical in talk of some domain of experience requires that we don't only examine individual linguistic expressions. We must also seek how different expressions instantiate different aspects of a rich, complex metaphorical concept. Clearly, both these areas are ripe for future research. Our exploration of the importance of metaphorical thought in several domains of language, thought, and human action illustrates that with careful systematic This conclusion does not imply that metaphor is everywhere or that all parts of some knowledge domain or human experience are completely structured in terms of metaphor. Instead, the studies we have described have demonstrated only that metaphor is an essential component to how people make sense of many aspects of their experience.

Finally, looking for metaphor in all the right ways demands that scholars seek linkages between language, thought, and action with ordinary patterns of embodied experience. Many of the most important, frequently employed source domains in conceptual metaphors arise from the body. We can find the roots of metaphorical thought and language by also systematically exploring the ways embodied experience get mapped onto many kinds of abstract concepts, which in turn get instantiated as both conventional and novel forms of language. In this way, looking for metaphor in embodied experience will shed light on how symbols, linguistic and otherwise, are grounded and appear to be meaningful to people in their everyday lives.

\section{References}

Allbritton, D., McKoon, G., \& Gerrig, R. (1995). Metaphor-based schemas and text comprehension: Making connections through conceptual metaphors. Journal of Experimental Psychology: Learning, Memory, and Cognition, 21, 612-625.

Basso, K. (1990). Western Apache language and culture. Tuscon: University of Arizona. Cooper, D. (1986). Metaphor. London: Blackwell.

DiGiacomo, S. (1992). Metaphor as illness: Postmodern dilemmas in the representation of body, mind, and disorder. Medical Anthropology, 14, 109-137.

Dryer, D. Christopher. (1999). Getting personal with computers: How to design personalities for agents. Applied Artificial Intelligence, 13, 273-295.

Gibbs, R. (1994). The poetics of mind: Figurative thought, language, and understanding. New York: Cambridge University Press.

Gibbs, R. (1996). Why many concepts are metaphorical. Cognition, 61, 309-319. Gibbs, R.

(in press). Embodied metaphor in performing and interpreting contact improvisational dance. Choreography and Dance.

Gibbs, R., \& Colston, H. (1995). The cognitive psychological reality of image schemas and their transformations. Cognitive Linguistics, 6, 347-378.

Gibbs, R., \& Franks, H. (in press). Embodied metaphor in women's narratives about their experiences with cancer. Health Communication, 
Gibbs, R., \& O’Brien, J. (1990). Idioms and mental imagery: The metaphorical motivation for idiomatic meaning. Cognition, 36, 35-68.

Gibbs, R., Bogdonovich, J., Sykes, J., \& Barr, D. (1997). Metaphor in idiom comprehension. Journal of Memory and Language, 37, 141-154.

Gibbs, R. \& Nascimento, S. (1996). How we talk when we talk about love: Metaphorical concepts and understanding love poetry. In R. Kreuz \& M. MacNealy (Eds.), Empirical and aesthetic approaches to literature (pp. 291-308). Norwood, NJ: Ablex.

Gibbs, R., \& Nayak, N. (1991). Why idioms mean what they do. Journal of Experimental Psychology. General, 120, 93-95.

Gibbs, R., \& O'Brien, J. (1990). Idioms and mental imagery: The metaphorical motivation for idiomatic meaning. Cognition, 36, 35-68.

Gibbs, R., Lima, P., \& Edson, F. (in press). Metaphor and human experience. Journal of Pragmatics, in press.

Gibbs, R., Strom, L., \& Spivey-Knowlton, M. (1997). Conceptual metaphors in mental imagery for proverbs. Journal of Mental Imagery, 21, 83-110.

Glucksberg, S., \& Keysar, B. (1990). Understanding metaphorical comparisons: Beyond similarity. Psychological Review, 97, 3-18.

Glucksberg, S., Brown, M., \& McGIone, M. (1993). Conceptual metaphors are not automatically accessed during idiom comprehension. Memory \& Cognition, 21, 711719.

Grice, H. P. (1975). Logic and conversation. In P. Cole \& J. Morgan (Eds.), Syntax and semantics: Vol. 3 (pp. 41-58). New York: Academic Press.

Gwryn, R. (1999). "Captain of my own ship:" Metaphor and the discourse of chronic illness.

In L. Cameron and G. Low (Eds.), Researching and applying metaphor (pp. 203-220).

Cambridge: Cambridge University Press.

Honeck, R. (1997). A proverb in mind. Mahwah, NJ: Erlbaum.

Johnson, M. (1987). The body in the mind. Chicago: University of Chicago Press.

Johnson, S. (1997). Interface culture. New York: HarperCollins.

Keysar, B., \& Bly, B. (1995). Intuitions of the transparency of idioms: Can you keep

a secret by spilling the beans? Journal of Memory and Language, 34, 89-109.

Kirmayer, L. (1992). The body's insistence of meaning: Metaphor as presentation and representation in illness experience. Medical Anthropology Quarterly, 6, 323-346.

Kreuz, R. \& Graesser, A. (1991). Aspects of idiom comprehension: Comment on Nayak and Gibbs. Journal of Experimental Psychology: General, 120, 90-92.

Lakoff, G. (1987). Women, fire, and dangerous things. Chicago: Chicago University Press.

Lakoff, G. (1990). The invariance hypothesis: Is abstract reason based on image-schemas? Cognitive Linguistics, 1, 39-74.

Lakoff, G, \& Johnson, M. (1980). Metaphors we live by. Chicago: Chicago University

Press. Lakoff, G., \& Nunez, R. ( 1998). Conceptual metaphor in mathematics. In J.P. Koenig (Ed.), Discourse and cognition (pp. 219-238). Stanford: CSLI Publications.

Lakoff, G,, \& Turner, M. (1989). More than cool reason: Afield guide to poetic metaphor. Chicago: University of Chicago Press.

Laurel, B. (1997). Interface agents: Metaphors with character. In Bayta Friedman (Ed.) Human values and the design of computer technology (pp. 207-219). New York, New York: Cambridge. 
Maglio, P, \& Matlock, T. (1999). The conceptual structure of information space. The Conceptual Structure of Information Space. In Munro, A., Benyon, D., \& Hook, K. (Eds.), Personal and social navigation of information space (pp. 155-173). Springer Verlag.

Metaphor Maglio, P, \& Matlock, T. (1998). Metaphors we surf the Web by. In Proceedings of the Workshop on Personal and Social Navigation in Information Space, Stockholm, Sweden.

Matlock, T, \& Maglio, P. (1999). Embodied experience in information spaces. Under review. Matlock,

T, \& Maglio, P. (1996). Apparent motion on the World Wide Web. Proceedings

of the Eighteenth Annual Cognitive Science Conference.

Mahwah, NJ: LEA.

Murphy, G. ( 1996). On metaphoric representation. Cognition, 60, 173-204.

Nass, C., Moon, Y, Morkes, E., Kim, E., \& Fogg, B.J. (1997). Computers are social actors: A review of current research. In Bayta Friedman (Ed.) Human values and the design of computer technology (pp. 137-162). New York, New York: Cambridge.

McGlone, M. (1996). Conceptual metaphors and figurative language interpretation: Food for thought? Journal of Memory and Lunguage, 35, 544-565.

Murphy, G. ( 1996). On metaphoric representation. Cognition, 60, 173-204.

Nayak, N, \& Gibbs, R. (1990). Conceptual knowledge in the interpretation of idioms. Journal of Experimental Psychology. General, 119, 315-330.

Norman, D. ( 1998). The invisible computer: Why good products can fail, the personal computer is so complex, and information appliances are the solution. Cambridge, MA: MIT Press.

Pfaff, K., Gibbs, R., \& Johnson, M. ( 1996). Metaphor in using and understanding euphemism and dysphemism. Applied Psycholinguistics, 18, 59-83.

Picard, R. (1997). Affective computing. Cambridge, MA: The MIT Press.

Quinn, N. (1992). The cultural basis of metaphor. In J. Fernandez (Ed.), Beyond metaphor. Stanford: Stanford University Press.

Searle, J. (1979). Metaphor. In A. Ortony (Ed.), Metaphor and thought (pp. 92-123). New York: Cambridge University Press.

Sontag, S. (1977). Illness as metaphor. New York: Farrar, Strauss, and Giroux. Scheper-

Hughs, N., \& Lock, M. (1987). The mindful body: A prolegomenon to future work in medical anthropology. Medical Anthropology Quarterly, 1,6-41.

Sweetser, E. (1990). From etymology to pragmatics: The mind-body metaphor in semantic structure and semantic change. Cambridge: Cambridge University Press.

Turner, M. (1991). Reading minds: The study of English in the age of cognitive science. Princeton: Princeton University Press.

Turner, M. (1996). The literary mind. New York: Oxford University Press.

Van Camp, J. (1996). Non-verbal metaphor: A non-explanation of meaning in dance. British Journal of Aesthetics, 36, 177-187.

Vervaeke, J., \& Kennedy, J. (1996). Metaphor in language and thought: Falsification and multiple meaning. Metaphor and Symbolic Activity, 11, 273-284.

Whittock, T. (1992). The role of metaphor in dance. British Journal of Aesthetics, 32, 242-249.

Whittock, T. (1997). Dance metaphors: A reply to Julie Van Camp. British Journal of Aesthetics, 37, 274-282. 